\title{
Medical Audit of Appendisectomies in Rural Based Tertiary Care Centre.
}

\author{
${ }^{1}$ Dr. S. Akhtar, ${ }^{2}$ Dr. S. A. Maimoon, ${ }^{3}$ Dr. S. D. Mahore \\ ${ }^{1}$ (Asstt. Professor Pathology), ${ }^{2}$ (Professor Pathology), ${ }^{3}$ (HOD pathology). \\ ${ }^{1,2,3}$ NKP Salve Institute of Medical Sciences, Research center and Lata Mangeshkar hospital Nagpur
}

\begin{abstract}
Acute appendicitis is one of the common surgical emergencies. There are various scoring systems in use to diagnose appendicitis. The aim of this study was to estimate the diagnostic accuracy of appendisectomies by using the modified Alvarado scoring system and histopathology for acute appendicitis. A prospective study was conducted on 100 patients hospitalized with abdominal pain suggestive of acute appendicitis and were subsequently operated, from June 2010 to July 2011 NKP SIMS \& LMH Nagpur. Both male and female patients from 7 years to 55 years of age were enrolled in the study. Preoperatively, modified Alvarado score was assigned to all, and results were compared with Histopatholgical diagnosis. Out of 100 operated patients 81 were diagnosed as acute appendicitis on the basis of Histopatholgical report. Patients with modified Alvarado score of 8-10, 5-7 and 1-4 have the accuracy of $90 \%, 79 \%$, and $0.4 \%$ respectively. In the higher score group the accuracy is more and acceptable. Lower score group should be kept under observation. Score sensitivity is more in male than female patients. This scoring system is a reliable and practicable diagnostic modality to increase the accuracy in diagnosis of acute appendicitis and thus to minimize unnecessary appendisectomies.
\end{abstract}

Key Words: Audit, Alvarado scoring system, acute appendicitis.

\section{Introduction}

The clinical diagnostic criteria as a classical signs and symptoms of acute appendicitis as a disease entity $^{1}$ was first reported by Reginald Heber Fits in 1886 .Still acute appendicitis has remained the most common acute surgical condition of the abdomen in all ages and evidently a common disease in surgical practice ${ }^{2}$. Even after a long period of about more than 120 years from its first depiction this common surgical disease continues to remain a diagnostic problem and can confuse most of the clinicians. Delay in diagnosis definitely increases the morbidity, mortality, and expenditure of management and in equivocal cases, destructive surgical approach too. Although being so common its diagnosis still remains challenge ${ }^{3,4}$ leading to a negative appendisectomies rate $20-40 \%$. In spite of advanced diagnostic modalities its diagnosis is mainly clinical one.

Various protocols have been introduced and tested by different researchers which include Lidverg, Fenyo, Christian, Ohman and Alvarado scoring system to make an early diagnosis of appendicitis. Alvarado in 1986 introduced a criterion for the diagnosis of acute appendicitis which was later modified to accommodate additional parameters along with original Alvarado scoring system ${ }^{6,7}$. The problem facing the surgeon is the identification of those patients with mild appendicitis who may benefit from conservative treatment. As the gold standard in diagnosis of acute appendicitis is histopathology. This study aims to review the Histopatholgical records of all appendices removed during emergency appendectomies and clinically diagnosed appendicitis; to identify the proportion of normal and appendicitis; and their sex ratio so that a prospective study can be carried out with conservative treatment with antibiotics, if justified.

\section{Methodology}

A retrospective study carried out at tertiary care rural hospital which is based on a detailed review of all Histopatholgical records and clinical details of all the appendices, which were removed during emergency appendectomies at NKP SIMS \& LMH NAGPUR from 1st January to 31st December 2011.AII postappendisectomy specimens received by department of pathology were reassessed with a review of all the records with the help of a histopathology consultant. The clinical Alvarado scoring was compared with appendices which were divided into three groups according to the following categories:

Category 1: Normal appendix;

Category 2: Mildly inflamed appendix;

Category3: Severely inflamed or perforated appendix.

Acute appendicitis is defined by some authors as the presence of transmural inflammation of ppendix or the presence of pus in the lumen of the appendix ${ }^{8}$. Riber and his group ${ }^{9}$ in Denmark define it as an appendix, which shows one or more of the following, features:

1.Granulocytes in the mucosa with focal or diffuse ulceration of the epithelium.

2.Crypt abscess with granulocytes in the epithelium. 
3.Granulocytes in the lumen with an infiltration into the epithelium.

4.Granulocytes on the serosa with appendicular abscess, with or without involvement of the mucosa. Granulocytes at the serosa or in the muscle layer without abscess and without involvement of the mucosa are not diagnosed as acute appendicitis, but as periappendicitis. Sternberg's Diagnostic Surgical Pathology textbook ${ }^{10}$ divides acute appendicitis into minimal, mild or early which shows; focal collection of neutrophils within the lumen and lamina propria; or focal erosions; cryptitis or crypt abscess formation; and severe appendicitis, which shows extensive suppuration extending deep into or through the appendicular wall. In the present study the Mildly Inflamed Appendix is defined as: An appendix which shows one or more of the following features (Category 2).

1. Mucosal erosion with superficial inflammation

2.Crypt abscess or cryptitis

3.Perivascular inflammation with cellular infiltration of parietal wall

4.Intraluminal inflammatory exudates

However, the inflammation should not reach the features of suppuration or gangrenous changes. Any appendix which did not show any of the above features is defined as Normal Appendix (Category 1). Whereas any appendix which showed more advanced inflammatory changes e.g., extensive suppuration extending deep into the wall of the appendix is defined as severe appendicitis (Category 3 ).

Using the scoring system for appendicitis, developed by Alvarado, each chart was retrospectively scored (Table I) ${ }^{6,7}$. The Alvarado score was then compared with pathology results. The incidence of patients with acute appendicitis according to Alvarado scores was defined based on pathology. Patients with a high probability of acute appendicitis were predicted to have high Alvarado scores; a low likelihood of appendicitis predicted to have low scores. Equivocal scores were least predictive of appendicitis. The sensitivity and specificity of the Alvarado scoring system were calculated for all scores. Using descriptive statistics, the Alvarado scores that correlated with positive pathology findings were determined, as well as Alvarado scores likely to correlate with negative pathology results. Equivocal scores having neither high sensitivity nor specificity for appendicitis were also calculated.

\section{Results}

During year from 1st January to 31st December 20112007, there were 100 appendisectomies carried out at NKP SIMS\& LMHNAGPUR. Age of the patients was from 7 years to 55 years with majority of patients in the third decade (34\%) followed by second decade (24\%) (Table-2).

Out of 100 patients $52(52 \%)$ were male and $48(48) \%$ were female .Clinically males were more susceptible than females with the mal-female ratio of 1.08: I (table-3).

All specimens of the 100 operated cases were reexamined Histopatholgical. The reports showed features of appendicitis in $81(81 \%)$ cases. The remaining $19(19 \%)$ patients did not show acute appendicitis. Out of 19 cases, 3 had ruptured ovarian cysts, one had salphingitis, 2 had pelvic inflammatory diseases, 2 had Meckel's diverticulitis and $11(11 \%)$ had no pathology.In this study the negative rate was $11 \%$ (Table-4). (table-5).

In this study, patients with scores $8-10,5-7$, and $1-4$ had $90 \%, 79 \%$ and $0.4 \%$ sensitivity respectively

Patients with the score 7 and above ,the sensitivity was $93 \%$ in male and $88 \%$ in females and over all sensitivity was $90 \%$ (Table-6).Patients with the score less than 7, the sensitivity was $77 \%$ in males and $60 \%$ in females and over all sensitivity was $69 \%$ (Table-7).

\section{Discussion}

Results of the study reveal that acute appendicitis was most common in the 21-30 years of age group (34\%). Followed by 11-20 years (24\%).Epidemiological studies have shown that appendicitis is more common in 10-29 years of age group ${ }^{8}$.Males are more susceptible than females. ${ }^{9}$

The diagnosis of acute appendicitis still remains a challenging task for surgeons. A negative rate of appendisectomies of $20 \%-40 \%$ is not an unusual finding in surgical literature ${ }^{10}$. Negative appendisectomies rate in this study was $19 \%$. The percentage of normal appendisectomies in various series varies from $8-33 \%{ }^{11,12,13}$ In a study, Lone et $\mathrm{al}^{14}$ observed negative appendisectomies rate was $17 \%$.In a prospective study of 215 adults and children, use of Alvarado score decrease an unusually high false positive appendisectomies rate of $44 \%$ to $14 \%$,For the entire modern Era of surgery many surgeons opined that maximum 15-20\% negative appendesectomies are acceptable ${ }^{15}$. Removal of normal appendices is expected to lower the rate of perforation and consequent mortality. On the other hand unnecessary appendisectomies carries long term risks to the patients ${ }^{16}$. Study reveal higher the score, more of its sensitivity, Patients with the Alvarado score ranges 8-10, 5-7 and 1-4 have accuracy $90 \%, 79 \%$, and $0.4 \%$ respectively (Table-5). Fengo et al ${ }^{17}$ reported a sensitivity of $90.2 \%$ and others reported a sensitivity of $73 \%$ with negative laparotomy rate of $17,5 \%$. In this study the sensitivity of the patients with the score 7 and above was $92 \%$ in male and $88 \%$ in female and the combined 
sensitivity was $90 \%$. Whereas it was $76 \%$ and $60 \%$ in male and female respectively and the combined sensitivity is $69 \%$ in the patients with score less than 7 . Study of Lone et al ${ }^{14}$ has shown the sensitivity of the patients with the score 7 and above was $94 \%$ in male and $81 \%$ in female and the combined sensitivity was $88 \%$. Whereas it was $69 \%$ in male and $63 \%$ in female and the combined sensitivity was $67 \%$ in the patients with score less than 7.

This study also reveals that this scoring system was more helpful in male patients by showing high accuracy rate as compared to female patients (Table-7). Lone et al ${ }^{14}$ has shown in their study that sensitivity in the same score was more in male than female patients. Lower values in female patients were due to presence of diseases in genital system i.e. Ovaries; salphingitis etc. ${ }^{18,19}$ In female's additional investigations could be required to confirm the diagnosis.

However, there are no signs, symptoms or laboratory tests that are $100 \%$ reliable in the diagnosis of acute appendicitis. In this study modified Alvarado scoring system showed that the accuracy of the diagnosis was very dependable and acceptable in higher scores but patients with lower scores should be under observation. The diagnostic score may be used as a guide to decide whether the patients need surgery or observation. Patients with score of 8 to 10 are almost certain to have appendicitis and they should undergo operation immediately. Patients with a score of 5 to 7 indicate probable appendicitis. They should be observed and evaluated every four to six hours, if the score remains the same or increases after this, re-evaluation is required and the patients may need operation. Patients with the score of 4 or less are very unlikely but not impossible to have appendicitis and they can be discharged from hospital after giving initial conservative treatment and with the advice to report again if symptoms persist or condition becomes worse.

\section{Conclusion}

In the diagnosis of acute appendicitis, the modified Alvarado score is a fast, simple, reliable, noninvasive, and safe diagnostic modality without extra expense and complications. It is very handy in peripheral hospitals where back up facilities are sparse. It can be very helpful for junior doctors provided it is applied purposefully and objectively in patients of abdominal emergencies. The application of this scoring system improves diagnostic accuracy and consequently reduces negative appendisectomies and thus reducing complication rates.

Tables:

Table-1 The Alvarado scoring system

\begin{tabular}{lll}
\hline & Clinical Feature & Value \\
\hline Symptoms & Migratory right iliac fossa pain Anorexia & 1 \\
& Nausea-vomiting & 1 \\
\multirow{3}{*}{ Signs } & Tenderness in Right iliac fossa & 1 \\
& Rebound tenderness & 2 \\
& Elevated temperature & 1 \\
Laboratory & Leukocytosis & 1 \\
& Shift to the left & 2 \\
\hline Total Score & & 1 \\
Interpretation of the modified Alvarado score: & $\mathbf{1 0}$ \\
Score 1-4: acute appendicitis very unlikely & \\
Score 5-7: acute appendicitis probably & \\
Score 8-10: acme appendicitis definite & \\
\hline
\end{tabular}

Table -2 Distribution of patients as per age group $(n=100)$.

\begin{tabular}{lll}
\hline Age group (years) & No. of Patients & Percentage \\
\hline Up to $\mathbf{1 0}$ & 07 & 07 \\
$\mathbf{1 1 - 2 0}$ & 24 & 24 \\
$\mathbf{2 1 - 3 0}$ & 34 & 34 \\
$\mathbf{3 1 - 4 0}$ & 18 & 18 \\
$\mathbf{4 1 - 5 0}$ & 11 & 11 \\
$\mathbf{5 1 - 6 0}$ & 06 & 06 \\
\hline Total & 100 & 100 \\
\hline
\end{tabular}

Table -3: Distribution of patients according to gender $(n=100)$.

\begin{tabular}{llll}
\hline Sex & No. of Patients & Percentage & Male: Female \\
\hline Male & 52 & 52 & $1.08: 1$ \\
Female & 48 & 48 & 100 \\
\hline Total & 100 & 100 \\
\hline
\end{tabular}


Table-4: Histopatholgical diagnostic findings $(n=100)$.

\begin{tabular}{|c|c|c|}
\hline Findings & No. of Patients & Percentage $(\%)$ \\
\hline \multicolumn{3}{|l|}{ Acute appendicitis } \\
\hline 1- Early acute (focal) appendicitis & 13 & 13 \\
\hline 2- Late acute appendicitis & 28 & 28 \\
\hline 3- Perforation appendicitis & 08 & 08 \\
\hline 4- Chronic appendicitis & 08 & 08 \\
\hline 5- $\quad$ Suppurative appendicitis & 20 & 20 \\
\hline 6- $\quad$ Gangrenous appendicitis & 04 & 04 \\
\hline Total & 81 & 81 \\
\hline \multicolumn{3}{|l|}{ Normal appendix with other diagnosis } \\
\hline 1- Rupture ovarian cyst & 03 & 03 \\
\hline 2- Salphingitis & 01 & 01 \\
\hline 3- Pelvic inflammatory disease & 02 & 02 \\
\hline 4- Meckl's diverticulitis & 02 & 02 \\
\hline 5- No pathology found & 11 & 11 \\
\hline Total & 19 & 19 \\
\hline
\end{tabular}

Table-5: Sensitivity of different score range groups $(n=100)$.

\begin{tabular}{lllll}
\hline Score & No. of Patients & Acute appendicitis & Normal appendix & Sensitivity \\
\hline $\mathbf{8 - 1 0}$ & 30 & 28 & 02 & $98 \%$ \\
$\mathbf{6 - 7}$ & 63 & 50 & 13 & $79 \%$ \\
$\mathbf{1 - 4}$ & 07 & 03 & 03 & $90 \%$ \\
\hline
\end{tabular}

Table-6: Sensitivity of modified Alvarado score 7 and above $(n=31)$

\begin{tabular}{lllll}
\hline Sex & No. of Patients with score 7 and $>7$ & Acute appendicitis & Normal appendix & Sensitivity \\
\hline Male & 14 & 13 & 01 & $93 \%$ \\
Female & 17 & 15 & 02 & $88 \%$ \\
\hline Total & 31 & 28 & 03 & $90 \%$ \\
\hline
\end{tabular}

Table-7: Sensitivity of modified Alvarado score $<7(n=46)$

\begin{tabular}{lllll}
\hline Sex & $\begin{array}{l}\text { No. of Patients with score } 7 \\
\text { and }<7\end{array}$ & Acute appendicitis & Normal appendix & Sensitivity \\
\hline Male & 26 & 20 & 06 & $77 \%$ \\
Female & 20 & 12 & 08 & $60 \%$ \\
\hline Total & 46 & 32 & 14 & $69 \%$ \\
\hline
\end{tabular}

\section{References}

[1]. Fitz RH. Perforating inflammation of the vermiform appendix with special reference to its early diagnosis and treatment Am J Med Sci 1886; 92:32-46.

[2]. Schwartz SI, Shires GT, Spencer Fe. Principles of Surgery. 6th ed. New York: McGraw-Hill Inc; 1994.p. 1307-18.

[3]. Wilcox RT, Willims L W. Have the evaluation and treatment of acute appendicitis changed with new technology Surg Clin N Am 1997; 77: 1355-70

[4]. Izbicki J R, Knoefel W T, Wilker 0 K, Mandelkow H K, Muller K, Siebeck M.

[5]. Accurate diagnosis of Acute Appendicitis: Analysis of 686 patients. Eur Journ Surg 1992; 158:227-31.

[6]. Khan I,Rehman A U, Application of Alvarado scoring system in diagnosis of Acute appendicitis. Journ Ayub Med Coil 2005; 17(3):41-44.

[7]. Alvarado A. A practical score for the early diagnosis of acute apendicitis. Ann Emerg Med 1986; 15: 557-564.

[8]. Macklin CP, Radcliffe GS, Merei JM, Stringer MD. A prospective evaluation of modified Alvarado scores for acute appendicitis in children. Ann R Coli Surg Eng11997; 79:203-205.

[9]. Marudanayagam R, Williams G, Rees B. Review of the pathological results of 2660

[10]. appendicectomy specimens. J Gastroenterol2006; 41(8): 745-749.

[11]. Riber C, Tonnesen H, Am A, Bjerregaard B. Observer variation in the assessment of the histopathologic diagnosis of acute appendicitis. Scand J Gastroenterol1999; 34(1): 46-49.

[12]. Mills S, (cd.) Sternberg's Diagnostic Surgical Pathology. 4th ed, vol 2, Lippincott Williams \& Wilkins, p. 1522.

[13]. Chang FC, Hogle HH, Welling DR. The fate of negative appendix. Am J Surg 1973; 126: 752-754.

[14]. Bell MJ, Bower RJ, Ternberg JL. Appendicectomy in childbood. Analysis of 105 negative appendixes. Am J Surg 1982; 144 : 335337.

[15]. Deutch AA, Shani N, Reiss R. Are some appendicectomies unnecessary? J R Coli Surg Edinb 1983; 28 : 35-40.

[16]. Lone NA, Shah M, Wani KA, Peer GQ. Modified Alvarado score in diagnosis of

[17]. acute appendicitis. Indian Journal for the Practising Doctor 2006; 3 (2).

[18]. Jones PF. Suspected acute appendicitis: trend in management over 30 years. B J Surg 2001; 88: 1570-77.

[19]. Kjossev KT, Losanoff JE. Duplicated vermiform appendix (case report). Br J Surg 1996; 83: 1259.

[20]. Fengo G, Lindberg G, Blind P, Enochsson L, Oberg A. Diagnostic decision in suspected acute appendicitis: validation of a simplified scoring system. Eur J Surg 1997; 163: 831- 8 .

[21]. Ohmann C, Yang 0, Frank C. Diagnostic score for acute appendicitis. Abdominal pain study group. Eur J Surg 1995; $161: 273-281$.

[22]. Lamparelli MJ Hoque HM, Pogson CH, Ball AB. A prospective evaluation of the combined use of modified Alvarado score with selective laparoscopy in adult females in the management of suspected appendicitis. Ann R Coli Surg Eng12000; 82 : $192-195$. 